\title{
A OBSERVAĈ̣̃O DO CÉU COMO PONTO DE PARTIDA E EIXO CENTRAL EM UM CURSO DE FORMAÇÃO CONTINUADA DE PROFESSORES
}

\author{
Paulo Sergio Bretones* \\ Maurício Compiani**

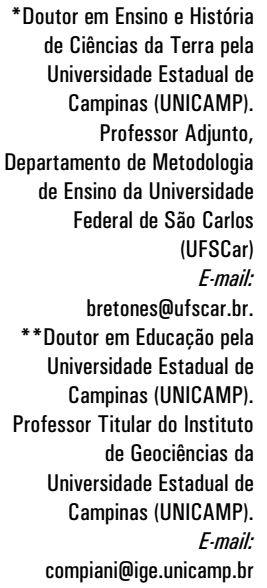

RESUMO: Este trabalho é parte da análise, sob o prisma da racionalidade prática, de um curso de Astronomia para formação continuada de professores. Verificou-se que, no tema da Observação do Céu, o desenvolvimento das atividades de ensino-aprendizagem foi norteado por dois aspectos da racionalidade prática. Como "ponto de partida", foram evidenciados o interesse inicial dos participantes, as perguntas iniciais, uma primeira aula prática de observação do céu e relatos de observações realizadas antes das aulas. Como "eixo central", ocorreram movimentos que começaram com práticas de aula do curso e seguiram para práticas pessoais; após relatos e desenvolvimento do assunto em aula, os participantes retornaram à prática com seus alunos, posteriormente relatadas, o que mostra que o currículo girou em torno da prática.

Palavras-chave: Astronomia; Observação do Céu; Formação de Professores; Professor Reflexivo; Racionalidade Prática.

\section{THE OBSERVATION OF THE SKY AS A STARTING POINT} AND CENTRAL AXIS IN A TRAINING COURSE FOR TEACHERS

ABSTRACT: This work is part of the analysis that used the model of practical rationality in an Astronomy course offered to teachers. There are two aspects of practical rationality for the sky observation. The first aspect is a "starting point" consisting of the initial interest of the participants, initial questions, a first class on sky observation and reports of observations made beforehand. The second aspect is a "central axis" that consisted of actions that began with practices in the classes and were followed by personal practices. Based on these teachers' reports of their practices, the contents of the course were further developed. The participants returned to their students and then reported again, demonstrating that curriculum revolved around practice.

Keywords: Astronomy; Observations of the Sky; Teacher Training; Reflective Teacher; Practical Rationality. 


\section{Introdução}

Os conteúdos de Astronomia há muito tempo estão presentes, de alguma maneira, nos programas oficiais ou nos livros didáticos, ao longo das reformas curriculares no Brasil.

Contudo, na legislação da formação de professores não existe determinação específica referente aos conteúdos de Astronomia. Os cursos superiores no Brasil oferecem pouquíssimas oportunidades para que os professores tenham formação inicial para lecionar conteúdos de Astronomia. São, portanto, necessárias estratégias nacionais para a implantação de cursos de formação continuada de professores.

Levando-se em conta o histórico da formação continuada de professores de Ciências no Brasil, pode-se verificar a abordagem de cursos de "treinamento" (KRASILCHIK, 1987; ROSA, 2004), "operações de salvamento”, "aulas de reforço" (ROSA, 2004), "reciclagem” ou "capacitação" (SCHNETZLER, 2000), baseados no modelo de formação profissional da racionalidade técnica, que supõe a superioridade do conhecimento teórico sobre os saberes práticos.

No modelo da racionalidade técnica, a prática docente lida com a solução de problemas por meio da aplicação de teorias e técnicas científicas, o professor é um técnico especialista e sua atividade é tipicamente instrumental. Nesse modelo, os níveis mais aplicados e próximos à prática subordinam-se aos mais teóricos e abstratos da ciência básica. Para Rosa (2004, p. 24), “... envolve um pensar calculista, próprio das estratégias de ensino, dos métodos, da eficiência e do rendimento, da teoria do 'êxito', da teoria educacional etc."

Schön (2000), ao criticar a racionalidade técnica, menciona que tal modelo desconsidera as zonas indeterminadas da prática: incerteza, singularidade e conflito de valores.

Tal especificidade da prática é abordada por Nóvoa (1995, p. 27):

As situações que os professores são obrigados a enfrentar (e a resolver) apresentam características únicas, exigindo, portanto respostas únicas: o profissional competente possui capacidades de autodesenvolvimento reflexivo. [...] A pedagogia científica tende a legitimar a razão instrumental? Os esforços de racionalização do ensino não se concretizam a partir de uma valorização dos saberes de que os professores são portadores, mas sim através de um esforço para impor novos saberes ditos científicos. A lógica da racionalidade técnica opõe-se sempre ao desenvolvimento de uma práxis reflexiva (NÓVOA, 1995, p. 27, grifos do autor).

No modelo da racionalidade prática, como chamado por Pérez Gómez (1995), a prática é o ponto de partida a partir do qual o professor analisa e interpreta suas atividades e elabora teorias. Para Rosa (2004, p. 24), tal modelo “... envolve a valorização inter-relacional, daquilo que é razoável, fundamenta e dá sentido à prática pedagógica".

Pérez Gómez (1995) destaca 12 aspectos da racionalidade prática: 
1) Tem a prática como eixo central.

2) Nega a separação entre teoria e prática.

3) Utiliza a prática como ponto de partida.

4) Não reproduz acriticamente esquemas.

5) Toma a prática como processo de investigação.

6) Possui caráter holístico.

7) Propõe atividades criativas.

8) Possibilita que o pensamento prático seja aprendido.

9) Ressalta a importância do tutor.

10) Propõe escolas de desenvolvimento profissional.

11) Valoriza formadores experientes, preocupados com a inovação.

12) Promove a integração da prática às ciências básicas e aplicadas.

$$
\text { Ainda segundo Pérez Gómez (1995), }
$$

\footnotetext{
Nega-se a separação artificial entre a teoria e a prática no âmbito profissional. Em primeiro lugar, só a partir de problemas concretos é que o conhecimento acadêmico teórico pode tornar-se útil e significativo para o aluno-mestre. Em segundo lugar, o conhecimento que se mobiliza para enfrentar as situações divergentes da prática é do tipo idiossincrático, construído lentamente pelo profissional no seu trabalho diário e na sua reflexão na e sobre a ação. O conhecimento das ciências básicas tem um indubitável valor instrumental, desde que se integre no pensamento prático do professor (PÉREZ GÓMEZ, 1995, p. 111).
}

Este trabalho é parte da análise, sob o prisma da racionalidade prática, de um curso de formação continuada de Astronomia para professores. Verificou-se que, no tema da Observação do Céu, o desenvolvimento das atividades de ensino-aprendizagem foi norteado por dois aspectos da racionalidade prática: a prática como ponto de partida e como eixo central.

No que se refere à prática como ponto de partida, segundo Pérez

\title{
Gómez:
}

\begin{abstract}
A prática deve mesmo constituir-se como ponto de partida do currículo de formação. Yinger (1986) afirma que o processo de formação dos professores deve começar pelo estudo e análise do ato de ensinar. Nos programas de formação o conhecimento deve reportar-se à prática e ao conjunto de problemas e interrogações que surgem no diálogo com as situações conflituosas do quotidiano educativo (PÉREZ GÓMEZ, 1995, p. 111).
\end{abstract}

Para o autor, a prática é tratada como "ato de ensinar", ou seja, a prática pedagógica dos professores. Levando-se em conta as ações e os relatos dos participantes ao longo do programa aqui estudado, verifica-se que, em muitos momentos, ocorre a aplicação dos conhecimentos obtidos de maneira quase imediata pelos participantes com seus alunos. Mas encara-se aqui a prática no sentido mais amplo, o da prática de observação, da experiência observacional do 
participante em ambientes e situações que não são de aulas do curso, nem atividades com seus próprios alunos.

Ainda conforme mostra Pérez Gómez:

A prática deve ser entendida como o eixo central do currículo da formação de professores. Contrariamente às teorias derivadas da racionalidade técnica, que situam a prática no final do currículo de modo a possibilitar uma aplicação dos conhecimentos adquiridos, a perspectiva artística considera prática como o núcleo à volta do qual gira todo o currículo acadêmico (Eisner, 1985) (PÉREZ GÓMEZ, 1995, p. 111).

Nesta proposta, a prática, encarada como eixo central do currículo, apresenta toda uma perspectiva de investigação, quando aplicada aos conteúdos de observação do céu, cuja teoria e demais ações, por assim dizer, giram ao seu redor.

Tal perspectiva aponta para a valorização da racionalidade prática como alternativa à racionalidade técnica e apresenta potenciais contribuições como metodologia para a formação continuada de professores.

Os vários aspectos da racionalidade prática, bem como a racionalidade técnica e a teoria relacionada à formação de professores, somente vieram a ser conhecidos pelo pesquisador após o curso, em razão da necessidade de aprofundamento teórico da pesquisa realizada. Isso mostra que, para a própria abordagem dada ao curso, iniciou-se pela prática dele mesmo, para depois teorizar a seu respeito, no que se refere à análise das ações apresentadas pelos participantes.

A prática, como ponto de partida e como eixo, foi investigada pela análise dos relatos das mobilizações propiciadas no desenvolvimento da programação do curso.

\section{Desenvolvimento do Curso}

Em 2002, o Instituto Superior de Ciências Aplicadas (ISCA), em Limeira, promoveu um curso de 46 horas sobre Astronomia para professores de Ciências e Geografia de $5^{\mathrm{a}}$ a $8^{\mathrm{a}}$ séries.

Ocorreram aulas semanais, durante 14 semanas, que abordaram os principais temas da Astronomia: História da Astronomia, Astronomia de Posição, Sistema Sol-Terra-Lua, Instrumentos, Sistema Solar, Estrelas e Galáxias. Ocorreram duas práticas de observação do céu, uma na escola e outra no Observatório do Morro Azul. Foram utilizados modelos de esfera celeste, estações do ano, fases da lua e eclipses; foi construído um kit de relógio de Sol e outros foram demonstrados. Após o curso, foi estabelecido um grupo de estudos e realizadas cinco reuniões, das quais participaram apenas cinco professores, identificados aqui como B, J, R, SS e W. As reuniões foram pautadas pelos relatos dos participantes e por seus próprios interesses no desenvolvimento de conteúdos. 
Com uma metodologia de estudo de caso, foram investigadas as mobilizações propiciadas pelo curso em ações e concepções dos participantes sobre Astronomia. Também foram investigados os papéis da racionalidade prática e do conhecimento específico em tais mobilizações. O programa desenvolvido e estudado leva em conta o referencial teórico do professor reflexivo (SCHÖN, 1995). Também se procurou relacionar, às várias fases do curso, os aspectos mencionados da racionalidade prática (PÉREZ GÓMEZ, 1995).

Os dados foram obtidos por meio de avaliações, entrevistas, relatos dos participantes, registros de aulas e reuniões, e foram analisados os relatos de ações extraclasse dos participantes e a sua relação com o desenvolvimento da programação do curso.

\section{Resultados}

\subsection{A prática como ponto de partida}

$\mathrm{Na}$ procura por estabelecer um olhar para a prática, como ponto de partida ao longo do curso, várias abordagens podem ser consideradas:

1) interesse inicial dos participantes pelo curso;

2) perguntas iniciais;

3) uma primeira aula prática de observação do céu;

4) relatos de observações realizadas antes das aulas.

A primeira abordagem implica considerar-se que o próprio interesse voluntário dos participantes do curso foi motivado pela busca de conhecimento, o que teve como ponto de partida a vida, a formação inicial e a prática pedagógica de cada um deles. Verificando-se os dados do questionário aplicado no início do curso, nota-se que, naquele momento, todos os participantes deram respostas ligadas à "aquisição de conhecimento", com relação aos motivos que os levaram a participar do curso.

A segunda abordagem envolve considerar-se que, mesmo antes de qualquer abordagem teórica ou do desenvolvimento do programa preestabelecido, existem perguntas e relatos dos participantes relacionados a práticas de observação do céu. Tais perguntas e relatos podem ser vistos, para aqueles que o fizeram, como ponto de partida, tendo em vista o curso do qual participariam a seguir.

Independentemente do programa seguido pelo curso, é muito natural que os participantes, por si sós, tenham ou aumentem seu interesse em observar mais o céu. Mesmo sendo observadores habituais ou tendo sido motivados pelo curso, os participantes, já nas primeiras aulas, apresentaram relatos sobre suas observações. Essas ações foram destacadas e analisadas a posteriori ao contexto em que ocorreram. 
Partir da prática é partir dos conhecimentos prévios dos participantes para a construção de novos saberes nas aulas e reuniões do projeto e na sua própria realidade como professores. Dando espaço para os relatos, podem-se conhecer novas situações das práticas em novos contextos encontrados pelos próprios participantes, conforme aponta Perrenoud:

Quando o ponto de partida é o das práticas, isso não significa necessariamente que devamos realizar um seminário de análise de práticas no sentido canônico. Trata-se apenas de saber de onde partimos, incitar todos a verbalizar suas representações e suas formas de ação. Aproximamo-nos do raciocínio da didática das ciências quando ela afirma que é preciso partir dos conhecimentos prévios do aprendiz, fundamentados ou não, para construir novos saberes. Chegamos, assim, aos trabalhos de transferência de conhecimentos, os quais tentam elucidar as condições em que os saberes podem ser mobilizados em novos contextos. Se partirmos das práticas, temos de ter tempo para escutar relatos, justificativas e itinerários (PERRENOUD, 2002, p. 179).

No decorrer do curso aqui estudado, não foi feito levantamento detalhado dos conhecimentos prévios dos participantes. Contudo, ao fazer um aprofundamento teórico da pesquisa realizada, verificou-se que, escutando os relatos dos participantes, foram construídos novos saberes, mobilizados em diversos novos contextos.

$\mathrm{Na}$ Aula 2, o participante $\mathrm{W}$ perguntou sobre a primeira estrela que surge ao pôr do Sol. E o que se vê de Vênus no observatório. Na Aula 4, relatou que não conseguiu ver meteoros em duas horas de observação na chácara. Sua pergunta e seu relato da observação na chácara mostram o interesse do participante pela observação do céu antes que o curso pudesse abordar o tema.

Uma hipótese para explicar o relato, na Aula 4, da tentativa do participante de observar meteoros, talvez seja a chuva de meteoros das Eta Aquáridas. O participante poderia ter tido conhecimento da ocorrência dessa chuva em um dos livros adotados no curso e entregue aos participantes ainda na Aula 3 (BRETONES, 1993), ou por outra fonte. Porém, o máximo da referida chuva de meteoros ocorreu no dia 4 de maio, uma semana e meia antes da aula em que se deu o relato. O participante, sem dúvida, poderia observar meteoros dessa radiante; eles, contudo, são visíveis de madrugada, e não se obtiveram informações quanto ao horário da observação realizada. Também não ocorreu ao professor do curso procurar, no momento do relato, associar a data à chuva ocorrida ou questionar o que teria levado o participante a observar meteoros.

$\mathrm{Na}$ Aula 5, W solicitou que o professor colocasse os nomes das estrelas em registro de observação que fez: "Aquele desenho que eu fiz do céu... gostaria que colocasse para mim os nomes das estrelas".

O relato da ação de fazer desenhos do céu mostra a obtenção de registros de observações e, portanto, uma construção por parte do participante. Ocorre que esses desenhos também diagnosticam que a observação do céu poderia ter sido feita, se as condições permitissem, logo no primeiro dia de 
curso, e a observação feita na Aula 5 teria sido, portanto, tardia. Porém, em cursos dessa natureza para professores, há uma grande dificuldade de adequação da prática de observação coletiva à agenda dos participantes.

Esta situação também remete à metodologia relatada por Lorenzoni (1988). Tal experiência refere-se a uma sequência de práticas de observação do céu com alunos, que tiveram início com uma folha trazida por um aluno na qual este havia desenhado uma constelação.

Segundo o autor, a partir das perguntas feitas pelo aluno que trouxe o desenho, foi sugerido à classe toda repetir a experiência. Foi proposto que os alunos se colocassem em círculo e, dois a dois, desenhassem um pedaço do horizonte, valorizando a percepção, as representações, o espaço e o tempo.

Também observaram a posição do pôr do Sol como meio de estudar o tempo e as direções determinadas com a experiência visual, permitindo a compreensão da duração do dia e da noite e do ciclo das estações. O autor também propõe outras possíveis observações, relativas: ao movimento da constelação de Órion em três momentos sucessivos em uma noite; às fases da Lua e sua posição no céu, durante duas semanas, na hora de deitar; e às posições de planetas, usando como referência as estrelas de certa constelação.

A terceira abordagem supõe considerar-se a primeira prática de observação do céu, na programação do curso como um todo e também como ponto de partida, tendo desencadeado uma série de práticas e conteúdos desenvolvidos ao longo da programação do curso.

Dessa forma, o grande impulso para ações relacionadas à observação do céu ocorreu a partir da observação realizada no começo da noite da Aula 5, nos fundos do colégio onde o curso se realizou, como mostra a foto da Figura 1. Naquela oportunidade, foram utilizadas fotocópias das faces Sul e Norte e do planisfério do céu daquela data, no final do mês de abril, além de planisférios rotativos.

Eram visíveis as constelações do Cruzeiro do Sul, Órion e Leão, entre outras. Foi feita a identificação de constelações e de estrelas mais brilhantes, em particular, Sírius, $\alpha$ e $\beta$ Centauri, Cástor e Pólux. Foi utilizada uma luneta de 60 mm com a qual se observaram a Lua e o planeta Júpiter. Ao final da atividade, sugeriu-se a possibilidade de práticas individuais de observação do céu para acompanhar os movimentos da esfera celeste e dos astros. Como sugestão inicial, solicitou-se que observassem o Cruzeiro do Sul e verificassem que tipo de movimento ele faz (para cima, para baixo, para esquerda ou direita). Também se propôs que tentassem identificar, em suas cidades e nas condições de que dispunham, outras estrelas dos mapas fornecidos. 
Figura 1: Observação do céu com utilização de mapas celestes e planisférios

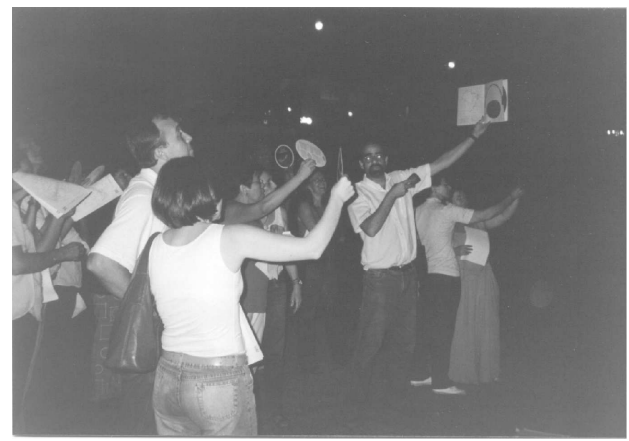

A sugestão de tais observações encontra correspondência na proposta de Bisard (1984, p. 182), quando se refere a atividades práticas em Astronomia para estudantes que não são das áreas científicas: "Uma das mais fáceis atividades que um instrutor pode pedir para estudantes é ir para fora em uma noite clara, observar o céu e responder as questões, 'O que você viu?' ou 'Você viu alguns movimentos?' [...]".

Solicitar aos participantes que observassem o movimento do Cruzeiro do Sul foi sugerir um aspecto da observação que poderiam fazer. Outros aspectos envolveriam verificar e comparar os brilhos das estrelas daquela constelação, as cores, em que medida o formato da constelação se parece com uma cruz, etc.

Dessa forma, com o objetivo de responder à pergunta: "Que movimento o Cruzeiro faz ao longo das horas?”, os participantes já tinham algo em mente, uma pergunta, um desafio.

Pode-se aqui fazer um paralelo da observação do céu com a forma que Compiani e Carneiro (1993) utilizam, quando discutem o papel didático das excursões geológicas:

\footnotetext{
É impossível observar algo sem que se estabeleça alguma interpretação prévia ou sem que se crie algum nível de conhecimento, ainda que bastante elementar. O campo, onde o conflito entre o exterior e o interior é mais intenso, possibilita a iniciação ao "fazer Geologia", a partir de formas muito simples e concretas de observação e interpretação da natureza na busca de informações, no entendimento dos fenômenos e na formulação de conceitos explicativos. Naturalmente, qualquer observação estará imbuída de um problema a resolver (COMPIANI; CARNEIRO, 1993, p. 91).
}

Mesmo que os participantes nunca tivessem identificado o Cruzeiro do Sul, a primeira observação realizada na Aula 5 propiciou um primeiro contato com o céu, um primeiro nível de conhecimento para que pudessem, em momento posterior, verificar o movimento da constelação e, mais adiante, formular conceitos para o entendimento do fenômeno.

Há ainda uma quarta abordagem da prática como ponto de partida no estudo aqui realizado. Em vários momentos, foram usados os relatos trazidos 
pelos participantes, que tiveram como origem a sua prática, seja individualmente, com amigos ou em família, seja em atividades com seus alunos.

Trata-se de um olhar mais minucioso para ações extraclasse que realizaram, em situações diferentes e fora do curso, motivadas por observações de diversas naturezas, de objetos celestes diferentes. Tais relatos de ações desencadearam explicações em aula e avanços na programação.

Para esta abordagem da prática como ponto de partida na busca da superação da racionalidade técnica na formação de professores, pode-se recorrer à contribuição dos educadores ingleses Lawrence Stenhouse $(1984,1987)$ e John Elliott (1990). Conforme Serrão (2002), estes autores consideram a prática docente como locus de produção de conhecimento, pois entendem a investigação como inerente ao exercício profissional.

Dessa forma, pode-se entender a prática como ponto de partida que gera problemas que, por sua vez, requerem soluções. Para a autora,

\begin{abstract}
... o professor, cotidianamente, depara-se com problemas oriundos de sua prática, que requerem soluções a fim de prosseguir seu trabalho. O professor recupera o que tem acumulado para solucionar os problemas encontrados. Assim, na tentativa de resolvêlos, produz necessariamente conhecimentos. O conhecimento, portanto, é produto da sua experiência. Nesse sentido, a teoria assume um papel de mediação entre uma prática passada e uma prática presente, visando a transformação dessa última, uma vez que ela se torna fonte de problemas que geram ações e saberes e o professor torna-se, então, um pesquisador. Desse modo, também fica evidente a singularidade de cada prática docente desenvolvida, pois o que guiará a ação de investigação do professor é o seu senso crítico, que se constitui por uma ética e uma estética configurada pela racionalidade prática (SERRÃO, 2002, p. 153-154, grifo da autora).
\end{abstract}

Fazendo-se uma análise de tais ações, pode-se considerar cada uma como sendo uma prática, um ponto de partida. Tais práticas geraram desenvolvimentos no programa de formação de professores aqui estudado.

Mais que levar em conta os relatos feitos pelos participantes, das aqui chamadas "ações extraclasse", procurou-se com isso valorizar as atividades que faziam parte da vida de cada um deles. Dessa forma, foi importante considerar o seu ponto de vista, quando refletiram sobre essa abordagem do programa do qual participaram.

As atividades extracurriculares foram tomadas como importantes pelos participantes, que as consideraram estimulantes, pois levam à participação, a fazer coisas de verdade, melhoram a autoimagem, propiciam o crescimento individual e o reconhecimento pelos colegas.

\title{
3.2. A prática como eixo central
}

Inicialmente, já era previsto seguir um programa preestabelecido, mas também sugerir ações extraclasse, além de também dar voz ao professor, procurando ouvir seus relatos a cada aula. Previam-se ainda entrevistas e reuniões após 
o curso, para verificar e estudar movimentos da própria prática dos participantes.

Dessa forma, o curso foi planejado e estruturado, mesmo antes de sua aplicação, tendo como eixo central uma sequência de conteúdos considerada clássica em cursos introdutórios e gerais de Astronomia, com os seguintes temas: História da Astronomia, Astronomia de Posição, Sistema Sol-Terra-Lua, Instrumentos, Sistema Solar, Estrelas e Galáxias.

Tal sequência de conteúdos, com caráter marcadamente tradicional e tecnicista, com um modelo fechado, acabou ocorrendo concomitantemente à abertura propiciada para relatos de ações dos participantes. Tais relatos mostraram ações individuais, com amigos e famílias dos participantes, e também aquelas realizadas com os alunos destes na sua prática pedagógica, em uma espiral reflexiva.

Dispunha-se, no tratamento dos dados desta pesquisa, de um conjunto de aulas e reuniões filmadas, bem como de entrevistas feitas com os participantes.

Procurando dar atenção aos relatos de ações dos participantes e aos respectivos efeitos observados nas aulas, verificou-se claramente o delineamento de uma série de movimentos ligados entre si e pautados na prática da observação do céu.

Com esse olhar, constatou-se que o procedimento de abertura das aulas para relatos contribuiu para romper com o modelo fechado inicial. Isso levou a movimentos relativamente harmônicos com o próprio programa inicialmente preparado e também com a busca de materiais, com os fenômenos astronômicos ocorridos no período e com o próprio cotidiano dos participantes.

Assim, considerando-se a prática como eixo central, foram destacados os movimentos observados tanto nas ações dos participantes quanto no desenvolvimento do programa do curso, e a própria abordagem ou a ênfase dada pelo pesquisador. Optou-se por estruturar este trabalho conforme a linha temporal da programação das aulas.

As ações relatadas serão apresentadas e destacadas ao longo da discussão a seguir.

Logo no início das aulas e no decorrer do curso, foram utilizados os relatos dos participantes, mas, devido à intenção de cumprir o programa, buscou-se estabelecer uma ligação entre tais relatos e o avanço da programação.

Contudo, mesmo procurando-se um desenvolvimento dos relatos, abrindo-se espaço para as falas dos participantes, fazendo sistematizações do conteúdo envolvido e também conexões dos relatos com o programa desenvolvido no curso, o professor-pesquisador voltava ao programa planejado inicialmente. Não se verificou, no curso aqui estudado, em toda sua extensão, que "todo" o currículo tivesse girado em volta da prática.

Entretanto, adotando-se um olhar voltado às práticas realizadas pelos participantes, percebem-se movimentos que começaram com práticas de aula do curso, seguiram para práticas pessoais e, após relatos e desenvolvimento do assunto em aula, retornaram para a prática pedagógica dos participantes com seus alunos. Assim, a prática pode ser vista como eixo, mais por conta das ações 
dos participantes e pela abertura permitida para seus relatos durante o curso, que pelo programa preestabelecido.

Várias perguntas referentes à observação do céu foram feitas logo nos primeiros dias de aula, o que indica a ocorrência de tais ações previamente ao curso, bem como a prática pedagógica decorrente da experiência de cada um. Contudo, foi na Aula 5, quando ocorreu uma atividade de reconhecimento do céu e foi dada uma sugestão para observação da constelação do Cruzeiro do Sul, que se verificou um grande incentivo à observação do céu pelos participantes.

$\mathrm{Na}$ Aula 6, com os relatos dos participantes de que o Cruzeiro faz um movimento horário (ao redor do polo celeste Sul), foi desenvolvido o conteúdo referente ao movimento diário da esfera celeste, e tal conhecimento foi sistematizado e usado como espinha dorsal do estudo aqui apresentado. Após essa aula, SS e W ministraram aula, fizeram atividades com seus alunos e relataram a esse respeito na Aula 9. A Figura 2 e as seguintes mostram as práticas como linhas horizontais. São apresentadas no texto a seguir e mostradas na figura as ações dos participantes: Atividades do curso (A), Práticas Pessoais (B), Práticas Pedagógicas ou com alunos (D), Relatos e Teoria desenvolvidos no curso (C) ou (E). Também são mencionadas as aulas $[A]$ e as reuniões $[R]$ em que ocorreram seus relatos.

$A$ atividade de observação do céu realizada no curso $(A)$ foi seguida de práticas pessoais dos participantes (B), relatos e desenvolvimento da Aula 6 (C). Depois se seguiram aulas dos participantes com seus alunos (D) e respectivos relatos na Aula 9 (E). A linha horizontal tracejada indica o eixo principal ao redor do qual as práticas giraram, bem como as aulas, quando tratavam de tais assuntos. Tal sequência poderia ser chamada de "modelo do virabrequim", devido à analogia com o componente de um motor, em que os vários componentes giram ao redor do eixo principal.

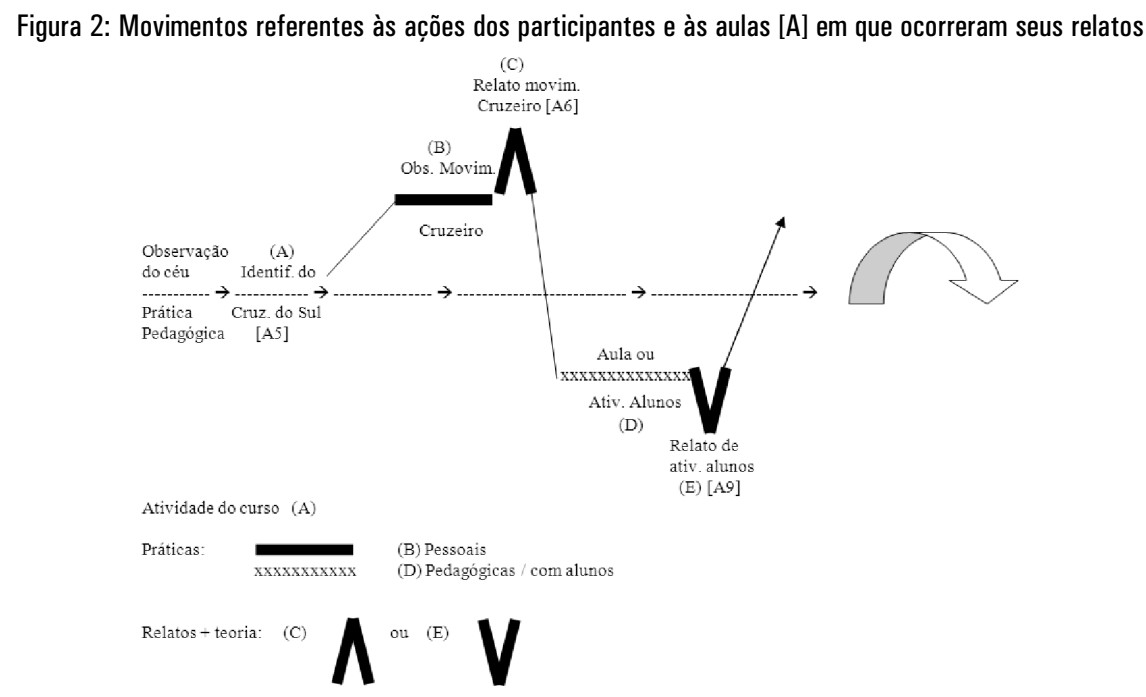


$\mathrm{Na}$ Aula 7, o participante SS perguntou qual era o planeta observado próximo à Lua na noite anterior (14/05/2002) (B). Tendo em vista perguntas desse tipo e relatos da observação de planetas no começo da noite, nessa mesma aula abriu-se espaço para serem trabalhados conteúdos referentes à sequência de conjunções ocorridas na época (C). Após essa aula, W ministrou aula, fez atividade com seus alunos (D) e relatou a esse respeito na Aula 10 (E). A Figura 3 mostra as práticas como linhas horizontais. A observação do planeta Vênus foi relatada na Aula 7, quando ocorreu o desenvolvimento de conteúdos sobre as conjunções de planetas. Depois se seguiu aula do participante W com seus alunos e respectivo relato na Aula 10. Também neste gráfico, a linha horizontal tracejada indica o eixo principal, ao redor do qual as práticas giraram, assim como as aulas, quando tratavam de tais assuntos.

Figura 3: Movimentos referentes às ações dos participantes e às aulas $[A]$ em que ocorreram seus relatos

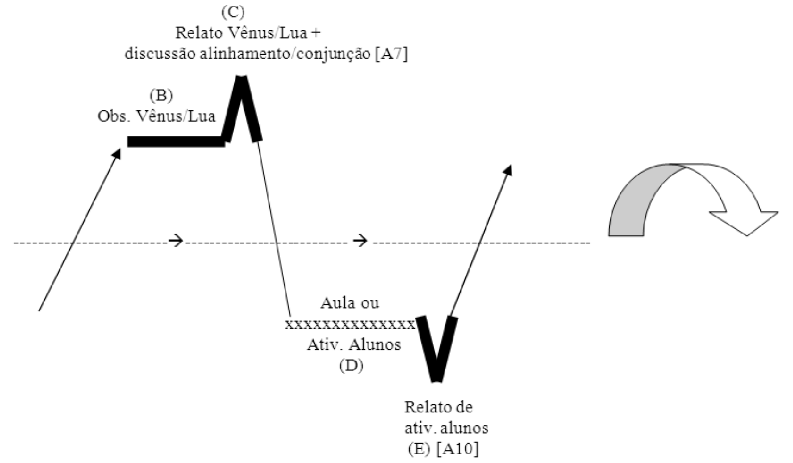

Ao longo de todo o curso, os participantes obtiveram e usaram mapas celestes de várias fontes, como planisférios, Atlas, sites e CDs. Foi discutida a relação das constelações com as estações do ano, o que particularmente foi trabalhado nas Aulas 8 e 12 e também nas reuniões após o curso. Os participantes visitaram o Observatório do Morro Azul, entre as Aulas 8 e 13 (B), quando identificaram constelações e observaram vários objetos celestes com telescópios, o que gerou a solicitação de efemérides para futuras observações do céu (C).

Ainda na Reunião 1, realizada após o curso, vários relatos foram feitos, referentes a observações das constelações de Escorpião e Órion e à diferença de suas posições em relação ao céu do começo do curso (E). Dessa forma, procurou-se avançar no conteúdo sobre o movimento anual da esfera celeste, usando as constelações visíveis nessa outra época do ano. Aproveitou-se para fazer a distribuição de mapas celestes atualizados, bem como para sugerir a observação de chuvas de meteoros. Isso motivou mais ações referentes a chuvas de meteoros observadas na época pelo participante $\mathrm{W}(\mathrm{B})$ e a consequente volta à consulta de mais mapas celestes por meio de Anuários, CDs e sites. Ainda na Reunião 5 (C), W relatou sobre o uso do CD e sobre a atividade referente aos movimentos do Cruzeiro do Sul que trabalhara com seus alunos (D). 
A Figura 4 mostra as práticas como linhas horizontais. A obtenção e o uso de mapas celestes, bem como as visitas ao Observatório foram seguidos de aula sobre constelações e solicitação de efemérides para futuras observações. A linha horizontal tracejada indica o eixo principal ao redor do qual as práticas giraram, bem como as aulas, quando tratavam de tais assuntos.

Figura 4: Movimentos referentes às ações dos participantes, à aula $[A]$ e às reuniões $[R]$ em que ocorreram seus relatos

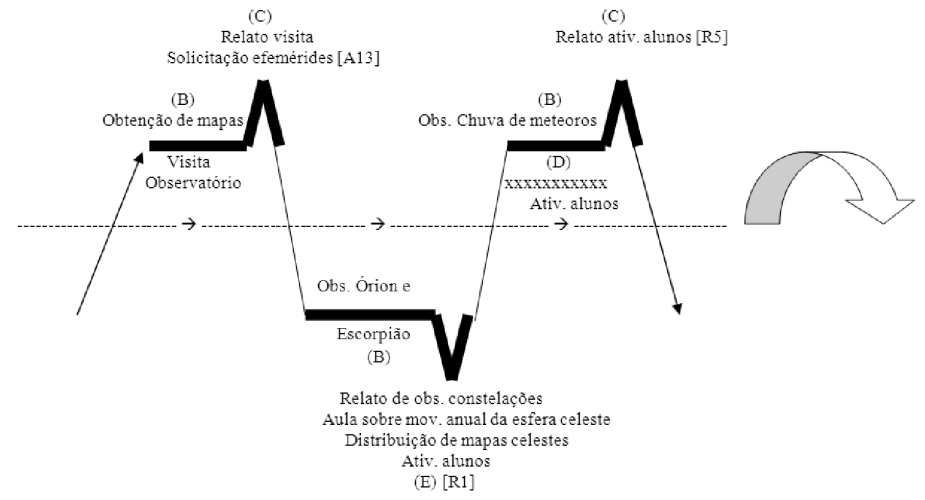

Após o curso, nas reuniões, as atividades estiveram mais centradas na prática, uma vez que o professor-pesquisador se preocupava mais com um programa preestabelecido.

Naqueles encontros, foram desenvolvidos vários temas: na Reunião 1, foram feitos relatos $(C)$ de observações das posições da Lua com relação ao planeta Vênus no céu do poente das noites anteriores (B). Tendo em vista as perguntas referentes ao aspecto ou às fases da Lua quando observada no céu, o tema dos movimentos da Lua foi discutido. Após essa Reunião, R ministrou aula para seus alunos (D) e relatou a esse respeito na Reunião 3 (E). (Figura 5)

Figura 5: Movimentos referentes às ações dos participantes e às reuniões $[R]$ em que ocorreram seus relatos

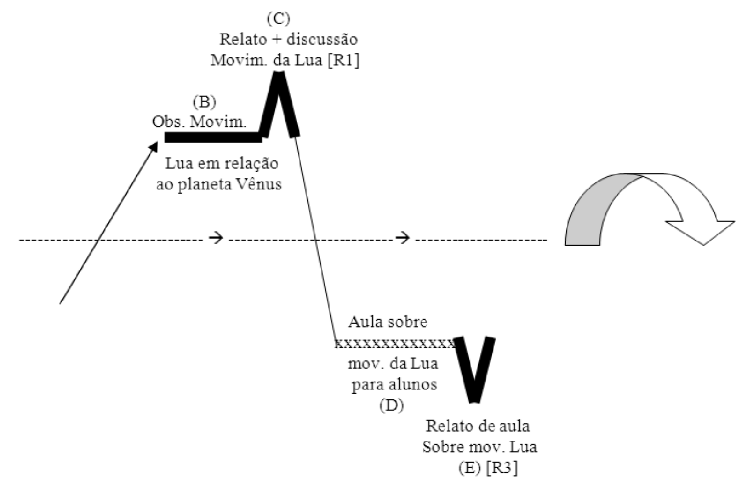


Também na Reunião 1, B apresentou modelo referente ao sistema SolTerra-Lua (C), que havia preparado (B) para ministrar aula para seus alunos. Foi discutido o uso do modelo, particularmente para as fases da Lua, aproveitandose o tema de discussão naquela oportunidade. Após essa Reunião, B ministrou aula para seus alunos (D) e relatou a esse respeito na Reunião 3, quando também apresentou fotografias de sua prática (E). (Figura 6)

Figura 6: Movimentos referentes às ações dos participantes e às reuniões [R] em que ocorreram seus relatos

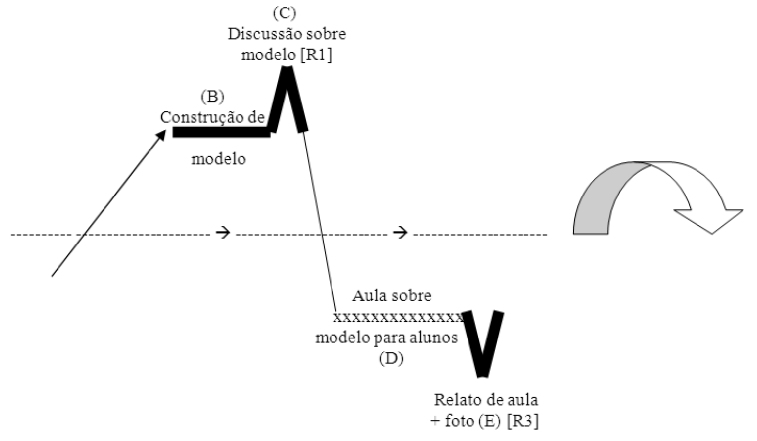

Esses movimentos verificados permitem constatar que, partindo das práticas dos participantes, ocorreram discussões e desenvolvimento de conteúdos nas aulas do curso, para posteriores práticas dos participantes, individualmente ou com seus alunos, mesmo sem ter ocorrido um planejamento inicial sobre isso. Assim, o projeto aqui estudado teve características do que Perrenoud (2002) chama "procedimento clínico".

No projeto desenvolvido, em aulas e reuniões, a única intenção já planejada previamente e mantida durante as aulas pelo professor-pesquisador era a de abrir espaço para as perguntas e os relatos dos participantes e procurar desenvolver novos conteúdos, quando possível. Mesmo assim, verificou-se um procedimento clínico, um momento de construção de novos saberes, o que foi constatado no estudo feito após o curso.

Nos movimentos verificados, observam-se a prática como eixo e a construção de saberes a partir dessa prática, desenvolvendo-se a teoria e, posteriormente, indo para a prática novamente; e assim sucessivamente, em uma espiral, como aponta Perrenoud:

No âmbito da formação profissional, o procedimento clínico representa uma grande mudança com relação ao modelo clássico, o qual estabelece que a teoria precede a ação que supostamente a aplicará mediante um pouco de intuição, de know-bow e de imaginação. No procedimento clínico, a teoria é desenvolvida a partir da ação em função de uma espiral: uma primeira construção conceitual fornece uma grade de leitura do que ocorre ou ocorreu, ao mesmo tempo em que a realidade enriquece e diferencia o modelo. 
Um procedimento clínico não substitui saberes eruditos por intuições inconsistentes e não dispensa a pesquisa fundamental e aplicada (PERRENOUD, 2002, p. 111).

Tal sequência não deve ser considerada a única aplicável a este tema, mas foi a verificada por esta pesquisa, e obteve-se uma espiral na aquisição de conteúdos da observação do céu.

\section{Conclusões}

O aspecto da prática como ponto de partida evidenciou-se de várias maneiras: pelo interesse inicial dos participantes pelo curso; pelas suas perguntas iniciais, formuladas antes do início da programação; por uma primeira aula prática de observação do céu; pelos relatos trazidos no início das aulas, originando desenvolvimento de conteúdos.

Um olhar voltado às práticas realizadas pelos participantes revela ter sido, de fato, a prática o eixo central. Isso se verificou mais pelas ações dos participantes e pela abertura permitida para seus relatos durante o curso do que pelo programa preestabelecido. Assim, foram observados movimentos que começaram com práticas de aula do curso, foram para práticas pessoais e, após relatos e desenvolvimento do assunto em aula, retornaram para a prática pedagógica dos participantes com os seus alunos. Iniciando-se com uma prática de observação do céu já programada pelo curso para os participantes, e com a sugestão dada pelo professor de observarem por sua própria conta, a partir daí, desenvolveuse todo um processo de construção de conhecimento por parte deles.

E tal foi o que ocorreu: dando-se espaço para que relatassem suas observações, que faziam sentido e tinham pertinência para os participantes uma vez que estes eram os protagonistas de tais ações -, a partir daí, em diversos momentos, foram construídos novos conceitos e prosseguiu-se com um programa que, afinal, era geral e introdutório sobre Astronomia. Isso foi verificado não apenas durante o curso, mas também durante as reuniões ocorridas posteriormente.

Conclui-se que o curso tomou um rumo peculiar, em que os princípios da racionalidade prática dominaram tanto o ensino do formador como as atividades desenvolvidas pelos professores; e os motivos para isso parecem ter sido as características próprias das práticas de observação do céu.

Isso se verificou, como este texto pôde evidenciar, mais pelas ações dos participantes e pela abertura permitida para seus relatos durante o curso que pelo programa preestabelecido. 


\section{REFERÊNCIAS BIBLIOGRÁFICAS}

BISARD, W. J. Practical activities in Astronomy for nonscience students. Journal of College Science Teaching, v. 14, n. 3, p. 181-183, Dec.-Jan. 1984-85.

BRETONES, P. S. Os segredos do Sistema Solar. São Paulo: Atual, 1993. 44p.

COMPIANI, M. \& CARNEIRO, Celso dal Ré. Os papéis didáticos das excursões geológicas. Enseñanza de las Ciencias de la Tierra, v. 1, n. 2, p. 90-98, 1993.

ELLIOT, J. La investigación-acción en educación. Madrid: Morata, 1990.

KRASILCHIK, M. O professor e o currículo das ciências. São Paulo: EPU: Editora da Universidade de São Paulo, 1987. 80p.

NÓVOA, António. Formação de professores e profissão docente. In: NÓVOA, A. (Org.). Os professores e a sua formação. Lisboa: Dom Quixote, 1995. p. 13-33.

PÉREZ GÓMEZ, A. O pensamento prático do professor: a formação do professor como profissional reflexivo. In: NÓVOA, A. (Org.). Os professores e a sua formação. Lisboa: Dom Quixote, 1995. p. 93-114.

PERRENOUD, P. A prática reflexiva no oficio de professor: profissionalização e razão pedagógica. Porto Alegre: Artmed, 2002.

ROSA, M. I. P. Investigação e ensino: articulações e possibilidades na formação de professores de ciências. Ijuí: Ed. Unijuí, 2004. 183p.

SCHNETZLER, R. P. O professor de Ciências: problemas e tendências de sua formação. In: SCHNETZLER, R. P. \& ARAGÃO, R. M. R. Ensino de ciências: fundamentos e abordagens. CAPES/UNIMEP, 2000. 182p.

SCHÖN, D. Formar professores como profissionais reflexivos. In: NÓVOA, A. (Org.). Os professores e a sua formação. Lisboa: Dom Quixote, 1995. p. 77-91.

SCHÖN, D. Educando o profissional reflexivo. Porto Alegre: Artes Médicas, 2000.

SERRÃO, M. I. B. Superando a racionalidade técnica na formação: sonho de uma noite de verão. In: PIMENTA, Selma Garrido; GHEDIN, Evandro. (Org.). Professor reflexivo no Brasil: gênese e crítica de um conceito. São Paulo: Cortez, 2002. p. 151-160.

STENHOUSE, L. Investigación y desarrollo del currículo. Madrid: Morata, 1984.

STENHOUSE, L. La investigación como base de la enseñanza. Madrid: Morata, 1987. 